\title{
Precarious Employment Is Not Associated with Increased Depressive Symptoms: A Cross-Sectional Study in Care Service Workers of Japan
}

\author{
Oa Tanaka, ${ }^{1}$ Eri Maeda, ${ }^{1}$ Masahito Fushimi, ${ }^{2,3}$ Toyoto Iwata, ${ }^{1}$ \\ Tetsuo Shimizu, ${ }^{3,4}$ Seiji Saito $^{3}$ and Katsuyuki Murata ${ }^{1,3}$ \\ ${ }^{1}$ Department of Environmental Health Sciences, Akita University Graduate School of Medicine, Akita, Akita, \\ Japan \\ ${ }^{2}$ Akita University Health Center, Akita, Akita, Japan \\ ${ }^{3}$ Akita Occupational Health Promotion Center, Akita, Akita, Japan \\ ${ }^{4}$ Department of Neuropsychiatry, Akita University Graduate School of Medicine, Akita, Akita, Japan
}

\begin{abstract}
Some epidemiological studies with a large number of subjects, like a national health study, reported that precarious employment was associated with increased depressive symptoms, but this hypothesis may not be applicable to precarious workers of all industry types. We examined the association between precarious employment and depressive symptoms in light of work-related stress in care work environments. The selfadministered questionnaire, composed of the Job Content Questionnaire based on the demand-controlsupport model and the Center of Epidemiological Studies Depression Scale (CES-D), was distributed, and a total of 1,338 permanent and 531 precarious employees responded to it with complete forms. In the precarious employees, scores of CES-D, job demand and job control were lower and supervisor support score was higher compared with the permanent employees, though there was no significant difference in the proportion of CES-D score $\geq 16$ between the two groups. Multivariate analysis with adjustment for possible confounders revealed that increased depressive symptoms were associated with low coworker support in the precarious employees and with high demand and low control at work, low support from supervisors and coworkers in the permanent employees. However, precarious employment was not significantly associated with depressive symptoms in the male or female employees. In conclusion, our results do not support the above hypothesis at least in care service workers. Such a hypothesis should be verified in employees of each industry separately. Instead, coworker support within each workplace appears to be important for the preventive strategy of depression in workers including precarious employees.
\end{abstract}

Keywords: care service; depressive symptoms; job stress; precarious employment; social support

Tohoku J. Exp. Med., 2017 September, 243 (1), 19-26. (C) 2017 Tohoku University Medical Press

\section{Introduction}

In developed countries, there has been a considerable increase of non-standard labor contracts, so-called, precarious employment (Kim et al. 2006; LaMontagne et al. 2014). As a matter of concern, some studies reported that precarious employment was associated with increased depressive symptoms or depression (Virtanen et al. 2005; QuesnelVallée et al. 2010; Ervasti et al. 2014; Fiori et al. 2016; Kim et al. 2016), and other demonstrated higher psychological morbidity among precarious workers compared with permanent workers (Kim et al. 2006; Kim et al. 2016); for instance, more days of work under temporary contract as well as frequent changes in temporary contract significantly increased the probability of developing mental health problems that need to be medically treated (Moscone et al. 2016). Is this really correct? Although epidemiological studies with a larger number of subjects are thought to offer the powerful evidence, they may lead to a wrong conclusion if an important confounder or stratification is overlooked. Especially in a national health study using the majority of subpopulation and the minority of one, it is possible that the former characteristics mask the latter. Regarding covariates/confounders in comparing between the precarious and permanent workers, at least, industry type should be considered and stratified if necessary, because they can directly affect socioeconomic conditions (Inoue et al. 2011a). For structuring a better strategy

Received July 10, 2017; revised and accepted August 18, 2017. Published online September 9, 2017; doi: 10.1620/tjem.243.19.

Correspondence: Katsuyuki Murata, M.D., Department of Environmental Health Sciences, Akita University Graduate School of Medicine, 1-1-1 Hondo, Akita, Akita 010-8543, Japan.

e-mail: winestem@med.akita-u.ac.jp 
against mental health, it is desirable to examine whether or not precarious employment is associated with psychological morbidity in male and female employees of various industries separately.

In Japan with rapid increase of social security costs due to an aging population, care work environments under the Long-Term Care Insurance Act, stipulating in-home and community-based service providers, facilities covered by long-term care insurance, etc., have been considered to be hard, dirty, and dangerous, and the wages remain depressed as compared to other industries (Suzumura et al. 2013). In addition, there are a large number of precarious employees in such workplaces. Apart from such work environments, after the demand-control-support model was innovated in the field of occupational health (Karasek 1979), it is believed that strong job stress may induce depressive symptoms. Madsen et al. (2017) indicated that job strain (the combination of high demand and low control at work) was modestly but significantly associated with an increased risk of clinical depression (relative risk $=1.77$ ). While working environments change drastically, a role of social support, i.e., support from supervisors and coworkers, also is drawing the attention. In regard to the significance of social support, the increased risk of insomnia (Nakata et al. 2004) and the role of preventing intention to leave a job and depressive symptoms (Saijo et al. 2016) have been emphasized. Nevertheless, little information is known about a relationship between the work-related stress and mental health in care workers with permanent or precarious employment. In this study, we summarized the feature of precarious employees, in comparison to permanent ones, working at care service facilities of Japan, and investigated the association between precarious employment and depressive symptoms, as well as whether or not the effect of work-related stress and family stress on depressive symptoms differed between the two groups.

\section{Methods}

\section{Design and study population}

A cross-sectional design was employed using employees of care service facilities in Akita prefecture, northeast Japan (i.e., rural areas far from the metropolis). We distributed self-administered, anonymous questionnaires to 197 care service facilities that were randomly selected from 601 care service facilities of the above prefecture, and facility staffs handed them to 2,727 employees in September 2015. The questionnaire included the Japanese version of the Job Content Questionnaire (JCQ) (Kawakami and Fujigaki 1996), the self-rating Center of Epidemiological Studies Depression Scale (CES-D) (Radloff 1977), and information about possible covariates and confounders. We retrieved 2,404 questionnaires each in a sealed envelope in November 2015 (response rate $=88.2 \%$ ), but some respondents were excluded because their forms were not completed. Finally, a total of 460 males and 1,409 females were enrolled in this study. The ethics committee of Japan Organization of Occupational Health and Safety approved this protocol.

\section{Measures}

The JCQ was used to measure job strain (job demand and job control) as described by Karasek et al. (1998), as well as other work organization factors including social support (Lipscomb et al. 2007). This questionnaire constituted a minimum set of 22 questions for the four major scales, and each question had a 4-point response ranging from 1 (strongly disagree) to 4 (strongly agree), and the factor-based and construct validity and internal consistency reliability of the Japanese version have been tested in several samples of Japanese workers (Kawakami et al. 1995). Depressive symptoms were assessed using the CES-D, which consists of 20 statements about feeling (e.g., happy, fearful, depressed) and behaviors (e.g., crying, eating, sleeping) and the subjects are required to indicate how often they have felt or behaved in these ways within the past week on a 4-point scale (from none of the time (0), to all of the time (3)). Total scores range from 0 to 60 , with higher scores indicating a greater number of symptoms. A total score of 16 or higher is considered to indicate depressed mood or probable depression (Lipscomb et al. 2007; Sugawara et al. 2017).

Possible confounders included age, sex, marital status (married, unmarried, or divorced/deceased), independent/dependent livelihood, job content (nursing care worker, manager or others) and employment status (permanent or precarious employment), and presence/absence of family stress, health anxiety, salary satisfied, and certification of care worker. Only 'never married' person was defined as unmarried. Regarding family stress (or health anxiety), the subjects reported whether they felt any stress/anxiety about family members and relatives (or about health) or not, by using yes $(=1)$ or no $(=0)$.

\section{Statistical analysis}

The significance of differences between the male and female employees and between the permanent and precarious employees was analyzed by Student $t$ test or $\chi^{2}$ test with Yates correction. The proportions of data with stratification were tested by Mantel-Haenszel $\chi^{2}$ test. Multiple logistic regression analysis was used to calculate the odds ratio (OR) and 95\% confidence interval (CI) of work-related stress (job demand, job control, supervisor support, and coworker support) and family stress on depressed mode (CES-D scores $\geq 16$ ) after adjusting for possible confounders (age, sex, marital status, livelihood status, job category, certification of care worker, employment status, salary satisfied, and health anxiety). All analyses with twosided $P$ value were performed using the Statistical Package for Bioscience (SPBS Ver. 9.68) (Murata and Yano 2002), and the significance level was set at $P<0.05$.

\section{Results}

Table 1 shows basal characteristics of the 1,869 participants with complete data and 2,404 participants including incomplete data. Significant sex differences were seen for age, job control, and proportions of independent livelihood, nursing care workers, managers, permanent employees, salary satisfied, family stress, and health anxiety, though there was no significant difference in the proportion of depressed mode between the male and female employees $(46.1 \%$ and $44.4 \%$, respectively; $\left.\chi^{2}=0.321, P=0.57\right)$. Likewise, significant differences between the permanent and precarious employees were seen for age, CES-D scores, job demand, job control, supervisor support, and proportions of indepen- 
Table 1. Basal characteristics of 1,869 employees of Japanese care service facilities.

\begin{tabular}{|c|c|c|c|c|c|c|}
\hline & \multicolumn{2}{|c|}{ Sex-specific } & \multicolumn{2}{|c|}{ Employment status-specific } & \multirow{2}{*}{\multicolumn{2}{|c|}{$\begin{array}{c}\text { All participants } \\
\text { including incomplete } \\
\text { data }\end{array}$}} \\
\hline & $\begin{array}{c}\text { Males } \\
(\mathrm{N}=460)\end{array}$ & $\begin{array}{c}\text { Females } \\
(\mathrm{N}=1,409)\end{array}$ & $\begin{array}{l}\text { Permanent } \\
\text { employees } \\
(\mathrm{N}=1,338)\end{array}$ & $\begin{array}{l}\text { Precarious } \\
\text { employees } \\
(\mathrm{N}=531)\end{array}$ & & \\
\hline & Mean \pm SD or $\%$ & Mean \pm SD or $\%$ & Mean \pm SD or $\%$ & Mean \pm SD or $\%$ & \multicolumn{2}{|c|}{ Mean \pm SD or $\%(N)$} \\
\hline Age (years) & $39.9 \pm 11.8^{* *}$ & $45.9 \pm 12.2^{* *}$ & $42.4 \pm 11.5^{* *}$ & $49.5 \pm 12.9^{* *}$ & $45.6 \pm 12.8$ & $(2,400)$ \\
\hline Females, \% & 0 & 100 & $70.0^{* *}$ & $88.9^{* *}$ & 76.1 & $(2,371)$ \\
\hline Marital status, $\%$ & & & & & & $(2,387)$ \\
\hline Married & 52.2 & 61.9 & 55.2 & 70.4 & 60.3 & \\
\hline Unmarried & 44.1 & 21.8 & 32.2 & 14.9 & 25.5 & \\
\hline Divorced or deceased & 3.7 & 16.3 & 12.6 & 14.7 & 14.2 & \\
\hline Independent livelihood, \% & $60.2 * *$ & $31.7 * *$ & $42.8 * *$ & $28.4 * *$ & 40.5 & $(2,375)$ \\
\hline Nursing care worker, \% & $62.4 * *$ & $51.6^{* *}$ & $58.9^{* *}$ & $42.6^{* *}$ & 55.2 & $(2,353)$ \\
\hline Manager, $\%$ & $14.1 * *$ & $8.3^{* *}$ & $12.9^{* *}$ & $1.7 * *$ & 9.4 & $(2,322)$ \\
\hline Permanent employment, \% & $87.2 * *$ & $66.5^{* *}$ & 100 & 0 & 70.2 & $(2,380)$ \\
\hline Certified care worker, $\%$ & 50.9 & 47.9 & $56.4 * *$ & $29.0 * *$ & 47.4 & $(2,404)$ \\
\hline Salary satisfied, $\%$ & $35.4 * *$ & $44.0 * *$ & $40.0 * *$ & $46.7 * *$ & 41.2 & $(2,403)$ \\
\hline Family stress, $\%$ & $16.1^{*}$ & $21.7 *$ & 20.0 & 20.9 & 19.3 & $(2,404)$ \\
\hline Health anxiety, $\%$ & $25.0 * *$ & $33.4^{* *}$ & $29.9 *$ & $35.0 *$ & 31.6 & $(2,404)$ \\
\hline Job demand score & $33.3 \pm 5.6$ & $32.8 \pm 5.3$ & $33.3 \pm 5.2 * *$ & $32.1 \pm 5.7 * *$ & $32.9 \pm 5.4$ & $(2,269)$ \\
\hline Job control score & $65.8 \pm 9.3^{*}$ & $64.6 \pm 9.2^{*}$ & $65.9 \pm 9.1 * *$ & $62.5 \pm 9.1 * *$ & $64.8 \pm 9.3$ & $(2,188)$ \\
\hline Supervisor support score & $10.9 \pm 3.0$ & $10.9 \pm 2.9$ & $10.8 \pm 3.0^{*}$ & $11.2 \pm 2.8^{*}$ & $10.8 \pm 3.0$ & $(2,294)$ \\
\hline Coworker support score & $11.2 \pm 2.4$ & $11.3 \pm 2.1$ & $11.2 \pm 2.2$ & $11.4 \pm 2.2$ & $11.2 \pm 2.2$ & $(2,305)$ \\
\hline CES-D score & $16.5 \pm 8.5$ & $16.1 \pm 7.7$ & $16.4 \pm 8.1^{*}$ & $15.6 \pm 7.4^{*}$ & $16.1 \pm 7.9$ & $(2,118)$ \\
\hline
\end{tabular}

$* P<0.05 ; * * P<0.01$ (Student $t$ test or $\chi^{2}$ test).

Table 2. Comparisons of basal characteristics and work-related stress between sex-specific employees with and without depressed mode (CES-D scores $\geq 16$ ).

\begin{tabular}{|c|c|c|c|c|c|c|}
\hline & \multicolumn{2}{|c|}{ Male employees } & \multirow[b]{2}{*}{$P$ value $^{\mathrm{a}}$} & \multicolumn{2}{|c|}{ Female employees } & \multirow[b]{2}{*}{$P$ value $^{\mathrm{a}}$} \\
\hline & $\begin{array}{c}\text { CES-D }<16 \\
(\mathrm{~N}=248) \\
\text { Mean } \pm \text { SD or } \%\end{array}$ & $\begin{array}{c}\text { CES-D } \geq 16 \\
(\mathrm{~N}=212) \\
\text { Mean } \pm \text { SD or } \%\end{array}$ & & $\begin{array}{c}\text { CES-D }<16 \\
(\mathrm{~N}=783) \\
\text { Mean } \pm \text { SD or } \%\end{array}$ & $\begin{array}{c}\text { CES-D } \geq 16 \\
(\mathrm{~N}=626) \\
\text { Mean } \pm \mathrm{SD} \text { or } \%\end{array}$ & \\
\hline Age (years) & $41 \pm 12$ & $38 \pm 11$ & 0.014 & $47 \pm 12$ & $44 \pm 12$ & $<0.001$ \\
\hline Marital status, $\%$ & & & 0.025 & & & $<0.001$ \\
\hline Married & 57.7 & 45.8 & & 69.9 & 51.9 & \\
\hline Unmarried & 38.3 & 50.9 & & 16.1 & 28.9 & \\
\hline Divorced or Deceased & 4.0 & 3.3 & & 14.0 & 19.2 & \\
\hline Independent livelihood, \% & 63.7 & 56.1 & 0.119 & 25.9 & 38.8 & $<0.001$ \\
\hline Nursing care workers, $\%$ & 56.9 & 68.9 & 0.011 & 47.3 & 57.0 & $<0.001$ \\
\hline Managers, $\%$ & 16.1 & 11.8 & 0.231 & 8.6 & 8.0 & 0.773 \\
\hline Permanent employment, \% & 87.9 & 86.3 & 0.714 & 64.1 & 69.5 & 0.039 \\
\hline Certified care workers, $\%$ & 48.9 & 53.3 & 0.384 & 48.3 & 47.4 & 0.797 \\
\hline Salary satisfied, $\%$ & 41.1 & 28.8 & 0.008 & 49.7 & 36.9 & $<0.001$ \\
\hline Family stress, $\%$ & 10.9 & 22.2 & 0.002 & 15.1 & 29.9 & $<0.001$ \\
\hline Health anxiety, $\%$ & 20.6 & 30.2 & 0.023 & 25.4 & 43.5 & $<0.001$ \\
\hline Job demand (score) & $32.2 \pm 5.0$ & $34.5 \pm 5.9$ & $<0.001$ & $32.5 \pm 5.1$ & $33.3 \pm 5.5$ & 0.003 \\
\hline Job control (score) & $67.2 \pm 9.2$ & $64.2 \pm 9.2$ & $<0.001$ & $65.9 \pm 9.1$ & $63.0 \pm 9.1$ & $<0.001$ \\
\hline Supervisor support (score) & $11.3 \pm 2.8$ & $10.5 \pm 3.2$ & 0.008 & $11.4 \pm 2.7$ & $10.2 \pm 3.0$ & $<0.001$ \\
\hline Coworker support (score) & $11.6 \pm 2.2$ & $10.8 \pm 2.5$ & $<0.001$ & $11.7 \pm 2.0$ & $10.8 \pm 2.2$ & $<0.001$ \\
\hline
\end{tabular}

a Student $t$ test or $\chi^{2}$ test.

dent livelihood, nursing care workers, managers, certified care workers, and salary satisfied, whereas there was no significant difference in the proportion of depressed mode between the two groups ( $46.2 \%$ and $41.4 \%$, respectively; $\chi^{2}$ $=3.288, P=0.067)$. The CES-D score (mean $\pm \mathrm{SD})$ of the 1,869 participants was calculated to be $16.2 \pm 7.9$.
Incidentally, the value was comparable to that $(17.1 \pm 9.7)$ of 979 hospital nurses in local cities of Hokkaido, Japan (Saijo et al. 2016), but significantly lower $(P<0.01)$.

The subjects were divided into 460 male and 1,409 female employees with and without depressed mode (Table 2). In both sexes, the subjects with depressed mode, in 
Table 3. Factors related to depressed mode (CES-D scores $\geq 16$ ) in 460 male and 1,409 female employees of care service facilities: results of multiple logistic regression analysis.

\begin{tabular}{|c|c|c|c|c|c|c|}
\hline & \multicolumn{2}{|c|}{ Male employees } & \multicolumn{2}{|c|}{ Female employees } & \multicolumn{2}{|c|}{ All employees ${ }^{\mathrm{a}}$} \\
\hline & OR & $95 \% \mathrm{CI}$ & OR & $95 \% \mathrm{CI}$ & OR & $95 \% \mathrm{CI}$ \\
\hline Age & 0.99 & $0.97-1.01$ & 0.98 & $0.97-0.99$ & 0.98 & $0.97-0.99$ \\
\hline \multicolumn{7}{|l|}{ Marital status } \\
\hline Married & 1.00 & & 1.00 & & 1.00 & \\
\hline Unmarried & 1.58 & $0.99-2.52$ & 1.65 & $1.18-2.31$ & 1.73 & $1.34-2.24$ \\
\hline Divorced or deceased & 1.36 & $0.45-4.10$ & 1.29 & $0.89-1.87$ & 1.42 & $1.02-1.97$ \\
\hline Independent livelihood & 0.99 & $0.63-1.57$ & 1.62 & $1.20-2.18$ & 1.39 & $1.09-1.76$ \\
\hline Nursing care worker & 1.31 & $0.81-2.11$ & 1.06 & $0.82-1.38$ & 1.13 & $0.90-1.41$ \\
\hline Manager & 1.13 & $0.61-2.09$ & 1.21 & $0.77-1.91$ & 1.16 & $0.81-1.67$ \\
\hline Permanent employment & 0.60 & $0.32-1.14$ & 1.11 & $0.85-1.45$ & 1.02 & $0.80-1.30$ \\
\hline Certified care worker & 1.04 & $0.66-1.62$ & 0.82 & $0.64-1.06$ & 0.85 & $0.69-1.06$ \\
\hline Salary satisfied & 0.65 & $0.43-1.01$ & 0.76 & $0.60-0.97$ & 0.74 & $0.60-0.91$ \\
\hline Family stress & 2.21 & $1.26-3.87$ & 2.70 & $2.03-3.60$ & 2.52 & $1.96-3.24$ \\
\hline Health anxiety & 1.53 & $0.95-2.48$ & 2.13 & $1.66-2.73$ & 1.95 & $1.57-2.43$ \\
\hline Job demand & 1.07 & $1.03-1.12$ & 1.01 & $0.99-1.03$ & 1.02 & $1.01-1.04$ \\
\hline Job control & 0.98 & $0.95-1.00$ & 0.98 & $0.96-0.99$ & 0.98 & $0.97-0.99$ \\
\hline Supervisor support & 1.01 & $0.94-1.10$ & 0.94 & $0.89-0.98$ & 0.95 & $0.91-0.99$ \\
\hline Coworker support & 0.87 & $0.78-0.96$ & 0.87 & $0.81-0.92$ & 0.87 & $0.82-0.92$ \\
\hline
\end{tabular}

${ }^{\text {aSex }}$ was adjusted $(\mathrm{OR}=1.13 ; 95 \% \mathrm{CI} 0.874-1.462)$.

comparison to those without it, were younger and showed higher scores of job demand, as well as higher proportions of nursing care workers, family stress, and health anxiety; by contrast, the former had lower scores of job control and supports from supervisors and coworkers, and were not satisfied with their salary. Factors related to depressed mode in the male and female employees are shown in Table 3. In the male employees, depressed mode was significantly associated with high job demand and low coworker support, together with family stress. In the female employees, depressed mode was significantly associated with low salary satisfaction, job control and supports from supervisors and coworkers, as well as young and unmarried women, independent livelihood, family stress, and health anxiety. When health anxiety was excluded from possible confounders because of the strong relation to depressed mode (sexadjusted $\mathrm{OR}=2.11,95 \%$ CI 1.73-2.58; Mantel-Haenszel $\chi^{2}$ test), all the significant associations remained unchanged though a variable of 'unmarried' men became statistically significant $(\mathrm{OR}=1.64,95 \% \mathrm{CI} 1.03-2.60)$. Given another criterion of CES-D score $\geq 19$ according to two recent studies (Wada et al. 2007), the OR of work-related stress in the males was 1.10 (95\% CI 1.05-1.15) for job demand, and those in the females were 0.98 (0.97-0.99) for job control, 0.95 (0.90-0.99) for supervisor support, and 0.85 (0.790.91 ) for coworker support.

Next, the subjects were divided into 1,338 permanent employees and 531 precarious employees with and without depressed mode (Table 4). In the permanent and precarious employees, the proportions of nursing care workers, family stress, and health anxiety were significantly higher in those with depressed mode than without it. Likewise, both the permanent and precarious employees with depressed mode had higher scores of job demand and lower scores of social supports from supervisors and coworkers. Table 5 presents the factors related to depressed mode in permanent and precarious employees. Both in the permanent and precarious employees, low coworker support, as well as unmarried persons, family stress, and health anxiety were significantly associated with depressed mode. In addition, high job demand and low job control were significantly associated with depressed mode only in the permanent employees. Still, all the significant associations remained unchanged when health anxiety was excluded from possible confounders because of the close relation to depressed mode (employment status-adjusted OR $=2.12,95 \%$ CI 1.74-2.59; Mantel-Haenszel $\chi^{2}$ test). Given another criterion of CES-D score $\geq 19$, the ORs of job stress in the permanent employees were 1.04 (95\% CI 1.02-1.07) for job demand, 0.98 (0.96-0.99) for job control, and 0.88 (0.83-0.94) for coworker support; those in the precarious employees were $1.04(1.00-1.08)$ for job demand and $0.86(0.77-0.96)$ for coworker support.

\section{Discussion}

This study focused on the impact of precarious employment on depressive status in care service facilities of Akita. The features of precarious employees, compared with permanent ones, were elder and showed low scores of job demand and job control, high score of supervisor support, low proportions of independent livelihood, nursing care workers, managers and certified care workers, and high proportion of salary satisfied. The CES-D score in the employees of care service facilities in Akita was significantly lower than that in hospital nurses of Hokkaido (Saijo et al. 2016), and the proportion of depressed mode in 
Table 4. Comparisons of basal characteristics and work-related stress between employment status-specific employees with and without depressed mode (CES-D scores $\geq 16$ ).

\begin{tabular}{|c|c|c|c|c|c|c|}
\hline & \multicolumn{2}{|c|}{ Permanent employees } & \multirow{3}{*}{$P$ value $^{\mathrm{a}}$} & \multicolumn{2}{|c|}{ Precarious employees } & \multirow{3}{*}{$P$ value $^{\mathrm{a}}$} \\
\hline & $\begin{array}{c}\text { CES-D < 16 } \\
(\mathrm{N}=720)\end{array}$ & $\begin{array}{c}\text { CES-D } \geq 16 \\
(\mathrm{~N}=618)\end{array}$ & & $\begin{array}{c}\text { CES-D < } 16 \\
(\mathrm{~N}=311)\end{array}$ & $\begin{array}{c}\text { CES-D } \geq 16 \\
(\mathrm{~N}=220)\end{array}$ & \\
\hline & Mean \pm SD or $\%$ & Mean \pm SD or $\%$ & & Mean \pm SD or $\%$ & Mean \pm SD or $\%$ & \\
\hline Age (years) & $43 \pm 12$ & $41 \pm 11$ & 0.009 & $52 \pm 12$ & $46 \pm 13$ & $<0.001$ \\
\hline Sex (female) & 69.7 & 70.4 & 0.837 & 90.4 & 86.8 & 0.256 \\
\hline Marital status & & & $<0.001$ & & & $<0.001$ \\
\hline Married & 61.9 & 47.2 & & 78.5 & 59.1 & \\
\hline Unmarried & 26.7 & 38.7 & & 9.3 & 22.7 & \\
\hline Divorced or deceased & 11.4 & 14.1 & & 12.2 & 18.2 & \\
\hline Independent livelihood & 39.3 & 46.8 & 0.007 & 25.1 & 33.2 & 0.052 \\
\hline Nursing care workers & 54.9 & 63.6 & 0.002 & 37.3 & 50.0 & 0.005 \\
\hline Managers & 13.9 & 11.8 & 0.295 & 2.3 & 0.9 & 0.402 \\
\hline Certified care workers & 56.3 & 56.6 & 0.931 & 30.2 & 27.3 & 0.521 \\
\hline Salary satisfied & 44.4 & 34.8 & $<0.001$ & 55.0 & 35.0 & $<0.001$ \\
\hline Family stress & 13.5 & 27.7 & $<0.001$ & 15.4 & 28.6 & 0.001 \\
\hline Health anxiety & 21.9 & 39.2 & $<0.001$ & 29.6 & 42.7 & 0.002 \\
\hline Job demand (score) & $32.8 \pm 4.9$ & $33.9 \pm 5.5$ & $<0.001$ & $31.6 \pm 5.3$ & $32.9 \pm 6.1$ & 0.008 \\
\hline Job control (score) & $67.6 \pm 8.8$ & $63.8 \pm 9.1$ & $<0.001$ & $63.0 \pm 9.2$ & $61.7 \pm 9.1$ & 0.122 \\
\hline Supervisor support (score) & $11.3 \pm 2,8$ & $10.1 \pm 3.1$ & $<0.001$ & $11.5 \pm 2.6$ & $10.8 \pm 3.0$ & 0.009 \\
\hline Coworker support (score) & $11.7 \pm 2.0$ & $10.7 \pm 2.3$ & $<0.001$ & $11.6 \pm 2.1$ & $11.0 \pm 2.3$ & 0.003 \\
\hline
\end{tabular}

aStudent $t$ test or $\chi^{2}$ test.

Table 5. Factors related to depressed mode (CES-D score $\geq 16$ ) in 1,338 permanent and 531 precarious employees of care service facilities: results of multiple logistic regression analysis.

\begin{tabular}{|c|c|c|c|c|}
\hline & \multicolumn{2}{|c|}{ Permanent employees } & \multicolumn{2}{|c|}{$\begin{array}{l}\text { Precarious } \\
\text { employees }\end{array}$} \\
\hline & OR & $95 \% \mathrm{CI}$ & OR & $95 \% \mathrm{CI}$ \\
\hline Age & 0.99 & $0.98-1.00$ & 0.97 & $0.95-0.99$ \\
\hline Sex (female) & 1.15 & $0.86-1.53$ & 0.85 & $0.44-1.64$ \\
\hline \multicolumn{5}{|l|}{ Marital status } \\
\hline Married & 1.00 & & 1.00 & \\
\hline Unmarried & 1.66 & $1.24-2.23$ & 2.18 & $1.17-4.05$ \\
\hline Divorced or deceased & 1.36 & $0.91-2.02$ & 1.40 & $0.75-2.62$ \\
\hline Independent livelihood & 1.33 & $1.02-1.75$ & 1.58 & $0.94-2.66$ \\
\hline Nursing care worker & 1.08 & $0.82-1.42$ & 1.17 & $0.78-1.76$ \\
\hline Manager & 1.20 & $0.82-1.75$ & 0.47 & $0.09-2.59$ \\
\hline Certified care worker & 0.88 & $0.68-1.13$ & 0.79 & $0.51-1.22$ \\
\hline Salary satisfied & 0.85 & $0.66-1.09$ & 0.53 & $0.36-0.79$ \\
\hline Family stress & 2.56 & $1.89-3.46$ & 2.51 & $1.56-4.02$ \\
\hline Health anxiety & 2.02 & $1.55-2.62$ & 1.88 & $1.25-2.83$ \\
\hline Job demand & 1.03 & $1.01-1.06$ & 1.02 & $0.99-1.06$ \\
\hline Job control & 0.97 & $0.95-0.98$ & 1.00 & $0.98-1.02$ \\
\hline Supervisor support & 0.95 & $0.90-0.99$ & 0.97 & $0.89-1.06$ \\
\hline Coworker support & 0.86 & $0.81-0.92$ & 0.88 & $0.80-0.98$ \\
\hline
\end{tabular}

females of the present study was significantly lower in the precarious employees $(40.5 \%)$ than in the permanent employees (46.4\%), though precarious employment was not significantly associated with depressed mode in the males or females after adjusting for work-related stress and other confounders (Table 3 ). These findings suggest that precarious employment itself would not be a key factor affecting depressive status, probably because most of the precarious employees of care service facilities did neither have a heavy responsibility for their work nor make their living alone. A longitudinal study also suggested that precarious employment was not harmful to mental health in an Australian cohort, specifically in older workers transitioning from stable permanent employment to casual employment (LaMontagne et al. 2014). On the contrary, some studies reported that precarious employment was associated with 
higher odds of depressive symptoms (Virtanen et al. 2005; Fiori et al. 2016; Kim et al. 2016), which is not consistent with ours. One explanation for the different conclusions would be that subjects of our study were employees of care service facilities and different from nationally representative samples of other studies. Taken together, it would be precipitous to generalize that precarious employment status results in depressive symptoms at present. Rather, since such effects of precarious employment differ in the industry type, further research is required to verify this hypothesis in employees of various industries separately.

In the present study, high psychological demands, low job control, and independent livelihood were significantly associated with depressed mode only among the permanent employees, though young and unmarried person, family stress, health anxiety, and coworker support were associated both in the permanent and precarious employees. Among the precarious employees, on the other hand, high satisfaction of salary was associated with allaying depressed mode (Table 5). The association of job strain with mental health problems, specifically depressive symptoms and depression, has been observed in permanent workers; for instance, fulltime workers of an electric equipment manufacturing company (Nakata et al. 2004), schoolteachers (Borrelli et al. 2014), employees of a governmental research institute (Inoue et al. 2011b), and nurses (Saijo et al. 2016). Thus, job strain appears to be applicable to permanent workers of a competitive society. By contrast, coworker support of the JCQ may be important for the prevention of depression in workers including precarious employees susceptible to psychosocial stressors.

Family/home stress seems to be elusive from appropriate evaluation, while there are a few of self-rating questionnaires like the Social Readjustment Rating Scale (Holmes and Rahe 1967). For this reason, little evidence has been established on a relationship between family/home stress and mentally ill-health. In this study, we found family stress significantly associated with depressed mode in the male and female employees. Especially, the OR of family stress was approximately 2.5 and the most powerful among the variables used (Tables 3 and 5). This is in agreement with the result by Phelan et al. (1991) indicating that domestic stress as well as occupational stress were associated with DSM-III-R major depression and current depressive symptoms in married professional and managerial employees of a major US corporation. Likewise, Maeda et al. (2015) reported that home stress was associated with autonomic dysfunction, i.e. elevated QT index $(\mathrm{OR}=2.68)$, in male employees belonging to a health insurance union of motor vehicle dealerships. Hypothetically, most of workers with depressive symptoms may have suffered family stress in addition to work-related stress at the early stage of the incidence. Although it is difficult for supervisors and coworkers at work to dissolve such family stress or workfamily conflict (McTernan et al. 2016; Sugawara et al. 2017), additional research is required to clarify this impact on depressive symptoms.

In the current study, although we failed to find a significant association between precarious employment and depressed mode in the male and female employees, several factors related to depressed mode, such as job demand, job control, and supervisor support, differed by sex. In the past report in Korea, the pattern of the relationship between precarious work and mental health differed by sex and females were significantly associated with poor mental health (Kim et al. 2006). Thus, it is recommended that data on mental health be analyzed and interpreted in males and females separately, because statistically significant results from all the population are affected by those from the majority of subpopulation as shown in Table 3. Namely, stratification and adjustment, in considering an important confounder like sex or industry type, resemble in the data analysis but greatly differ in interpretation of the result.

A major strength of this study is that the response rate was $88.2 \%$ for the 2,727 employees of care service facilities selected randomly; for this reason, so many participants would reduce inaccuracy resulting from random variation. In addition, even when the cutoff score of depressed mode (i.e., CES-D score $\geq 16$ ) was changed to the score $\geq 19$ as recommended by a recent study on Japanese workers (Wada et al. 2007), the main findings were almost similar. On the other hand, this study may have some limitations. Of the 2,404 participants, 535 (22.3\%) had some incomplete forms of the questionnaire and were excluded from the analysis. In this case, the values (i.e., mean $\pm \mathrm{SD}$ or \%) of all participants including incomplete data shown in Table 1 did not significantly differ from those of the current 1,869 participants except for age $(P<0.01)$. Due to the cross-sectional design, the directions of associations should be interpreted carefully; whereas, we conformed to the same direction of causality as many previous studies (Theorell et al. 2015). We did not have socioeconomic and educational data which might distort our results (Loerbroks et al. 2017), but the subjects were in a homogenous setting because of the same type of industry in culturally and economically similar areas. Finally, potential confounders, such as age, sex, job category, and salary satisfaction, were considered in the data analysis; in addition, our results remained unchanged even when health anxiety that might reflect depressed mode was excluded from explanatory variables. Thus, it appears that our data, despite the presence of missing values, were not heavily influenced by selection bias, measurement bias or confounders.

On the other hand, the wages of care work environments in Japan generally remain depressed under the LongTerm Care Insurance Act, though various socioeconomic conditions differ considerably between Akita and Tokyo prefectures. In fact, according to the social indicators by prefecture in 2013 (Statistics Bureau, Ministry of Internal Affairs and Communications 2017), prefectural revenue per population, ratio of owned houses, and proportion of persons aged 65 and above were 2,463,000 JP $¥ 78.1 \%$ and 
$31.6 \%$ in Akita, respectively, compared with 4,508,000 JP¥, $45.8 \%$ and $21.9 \%$ in Tokyo, and 3,065,000 JP¥, $61.7 \%$ and $25.1 \%$ in Japan. For this reason, the target population to refer our results obtained from the permanent and precarious employees of care service facilities in Akita may be limited in Japan not including the metropolis.

In conclusion, although some researchers suggest that precarious employment leads to depressive symptoms, it would not be a key factor affecting depressive status at least in care work environments; therefore, researchers must take notice of the industry type when analyzing such data. On the other hand, coworker support within each workplace appears to be important for the preventive strategy of depression not only in permanent workers but also precarious workers. In addition, particular attention should be paid to family stress in regard to the incidence of depression.

\section{Acknowledgments}

We would like to thank Dr. Yasutsugu Kudo, Mr. Masayuki Seki, Mr. Tomokazu Asanuma, and Mr. Hiroshi Goto for their assistance to data collection.

\section{Conflict of Interest}

The authors declare no conflict of interest.

\section{References}

Borrelli, I., Benevene, P., Fiorilli, G., D’Amelio, F. \& Pozzi, G. (2014) Working conditions and mental health in teachers: a preliminary study. Occup. Med., 64, 530-532.

Ervasti, J., Vahtera, J., Virtanen, P., Pentti, J., Oksanen, T., Ahola, K., Kivimäki, M. \& Virtanen, M. (2014) Is temporary employment a risk factor for work disability due to depressive disorders and delayed return to work? The Finnish Public Sector Study. Scand. J. Work Environ. Health, 40, 343-352.

Fiori, F., Rinesi, F., Spizzichino, D. \& Di Giorgio, G. (2016) Employment insecurity and mental health during the economic recession: an analysis of the young adult labour force in Italy. Soc. Sci. Med., 153, 90-98.

Holmes, T.H. \& Rahe, R.H. (1967) The social readjustment rating scale. J. Psychosom. Res., 11, 213-218.

Inoue, M., Nishikitani, M., Tsurugano, S. \& Yano, E. (2011a) The health of permanent workers and workers with precarious employment: a literature review. Sangyo Eiseigaku Zasshi, 53, 117-139.

Inoue, M., Tsurugano, S. \& Yano, E. (2011b) Job stress and mental health of permanent and fixed-term workers measured by effort-reward imbalance model, depressive complaints, and clinic utilization. J. Occup. Health, 53, 93-101.

Karasek, R.A. (1979) Job demands, job decision latitude and mental strain: implication for job redesign. Adm. Sci. Q., 24, 285-308.

Karasek, R., Brisson, C., Kawakami, N., Houtman, I., Bongers, P. \& Amick, B. (1998) The job content questionnaire (JCQ): an instrument for internationally comparative assessments of psychosocial job characteristics. J. Occup. Health Psychol., 3, 322-355.

Kawakami, N. \& Fujigaki, Y. (1996) Reliability and validity of the Japanese version of job content questionnaire: replication and extension in computer company employee. Ind. Health, 34, 295-306.

Kawakami, N., Kobayashi, F., Araki, S., Haratani, T. \& Furui, H. (1995) Assessment of job stress dimensions based on the job demands-control model of employees of telecommunication and electric power companies in Japan: reliability and validity of the Japanese version of the Job Content Questionnaire. Int. J. Behav. Med., 2, 358-375.

Kim, I.H., Muntaner, C., Khang, Y.H., Paek, D. \& Cho, S.I. (2006) The relationship between nonstandard working and mental health in a representative sample of the South Korean population. Soc. Sci. Med., 63, 566-574.

Kim, W., Park, E.C., Lee, T.H. \& Kim, T.H. (2016) Effect of working hours and precarious employment on depressive symptoms in South Korean employees: a longitudinal study. Occup. Environ. Med., 73, 816-822.

LaMontagne, A.D., Milner, A., Krnjacki, L., Kavanagh, A.M., Blakely, T.A. \& Bentley, R. (2014) Employment arrangements and mental health in a cohort of working Australians: are transitions from permanent to temporary employment associated with changes in mental health? Am. J. Epidemiol., 179, 14671476.

Lipscomb, H.J., Dement, J.M., Epling, C.A., Gaynes, B.N., McDonald, M.A. \& Schoenfisch, A.L. (2007) Depressive symptoms among working women in rural North Carolina: a comparison of women in poultry processing and other lowwage jobs. Int. J. Law Psychiatry, 30, 284-298.

Loerbroks, A., Ding, H., Han, W., Wang, H., Wu, J.P., Yang, L., Angerer, P. \& Li, J. (2017) Work stress, family stress and asthma: a cross-sectional study among women in China. Int. Arch. Occup. Environ. Health, 90, 349-356.

Madsen, I.E.H., Nyberg, S.T., Magnusson Hanson, L.L., Ferrie, J.E., Ahola, K., Alfredsson, L., Batty, G.D., Bjorner, J.B., Borritz, M., Burr, H., Chastang, J.F., de Graaf, R., Dragano, N., Hamer, M., Jokela, M., et al. (2017) Job strain as a risk factor for clinical depression: systematic review and metaanalysis with additional individual participant data. Psychol. Med., 47, 1342-1356.

Maeda, E., Iwata, T. \& Murata, K. (2015) Effects of work stress and home stress on autonomic nervous function in Japanese male workers. Ind. Health, 53, 132-138.

McTernan, W.P., Dollard, M.F., Tuckey, M.R. \& Vandenberg, R.J. (2016) Enhanced co-worker social support in isolated work groups and its mitigating role on the work-family conflictdepression loss spiral. Int. J. Environ. Res. Public Health, 13, 382.

Moscone, F., Tosetti, E. \& Vittadini, G. (2016) The impact of precarious employment on mental health: the case of Italy. Soc. Sci. Med., 158, 86-95.

Murata, K. \& Yano, E. (2002) Medical Statistics for EvidenceBased Medicine with SPBS User's Guide, Nankodo Publisher, Tokyo.

Nakata, A., Haratani, T., Takahashi, M., Kawakami, N., Arito, H., Kobayashi, F. \& Araki, S. (2004) Job stress, social support, and prevalence of insomnia in a population of Japanese daytime workers. Soc. Sci. Med., 59, 1719-1730.

Phelan, J., Schwartz, J.E., Bromet, E.J., Dew, M.A., Parkinson, D.K., Schulberg, H.C., Dunn, L.O., Blane, H. \& Curtis, E.C. (1991) Work stress, family stress and depression in professional and managerial employees. Psychol. Med., 21, 999-1012.

Quesnel-Vallée, A., DeHaney, S. \& Ciampi, A. (2010) Temporary work and depressive symptoms: a propensity score analysis. Soc. Sci. Med., 70, 1982-1987.

Radloff, L.S. (1977) The CES-D scale: a self-report depression scale for research in the general population. Appl. Psychol. Meas., 1, 385-401.

Saijo, Y., Yoshioka, E., Kawanishi, Y., Nakagi, Y., Itoh, T. \& Yoshida, T. (2016) Relationships of job demand, job control, and social support on intention to leave and depressive symptoms in Japanese nurses. Ind. Health, 54, 32-41.

Statistics Bureau, Ministry of Internal Affairs and Communications (2017) Social Indicators by Prefecture in 2013. 
[Cited: July 20, 2017].

http://www.e-stat.go.jp/

[Accessed: July 20, 2017].

Sugawara, N., Danjo, K., Furukori, H., Sato, Y., Tomita, T., Fujii, A., Nakagami, T., Kitaoka, K. \& Yasui-Furukori, N. (2017) Work-family conflict as a mediator between occupational stress and psychological health among mental health nurses in Japan. Neuropsychiatr. Dis. Treat., 13, 779-784.

Suzumura, M., Fushiki, Y., Kobayashi, K., Oura, A., Suzumura, S., Yamashita, M. \& Mori, M. (2013) A cross-sectional study on association of work environment, coping style, and other risk factors with depression among caregivers in group homes in Japan. Ind. Health, 51, 417-423.
Theorell, T., Hammarström, A., Aronsson, G., Träskman Bendz, L., Grape, T., Hogstedt, C., Marteinsdottir, I., Skoog, I. \& Hall, C. (2015) A systematic review including meta-analysis of work environment and depressive symptoms. BMC Public Health, 15, 738 .

Virtanen, M., Kivimäki, M., Joensuu, M., Virtanen, P., Elovainio, M. \& Vahtera, J. (2005) Temporary employment and health: a review. Int. J. Epidemiol., 34, 610-622.

Wada, K., Tanaka, K., Theriault, G., Satoh, T., Mimura, M., Miyaoka, H. \& Aizawa, Y. (2007) Validity of the center for epidemiologic studies depression scale as a screening instrument of major depressive disorder among Japanese workers. Am. J. Ind. Med., 50, 8-12. 